\title{
Preliminary Research on the 3D Printing Technology in the Indoor Soft Packaging Design
}

\author{
$\mathrm{Yu} \mathrm{Xiao}$ \\ Huanggang Normal College \\ Huanggang, China
}

\begin{abstract}
The 3D printing technology, appeared in the 1990s, has become one of the most rapid developing sciences and technologies nowadays. Its incomparable ultra-high efficiency will bring irreversible changes in the industry. Its complex and efficient way of finished products is bound to bring a major reshuffle of many industries including architectural design, industrial design, indoor design, fashion design, and other realms of art. As the global 3D printing technology develops vigorously and the country fully supports the research and development of relevant technical materials, this paper intends to analyze the influence and technology application of the technology on indoor soft packaging design market.
\end{abstract}

Keywords-3D printing technology; printing platform; indoor soft packaging; development status

\section{INTRODUCTION}

Soft outfit design, subordinate to interior design, is an important part of the design division. Sub-items consist of movable decorations such as furniture, lighting, furnishings, and the design process is an extremely test for the designers' professional abilities and appreciation levels. 3d printing technology may meet customers' requirements accurately, no doubt the customized service for individuals in soft outfit will rare chance for soft outfit designers to upgrade the design level and exert the imagination freely. Though the technology is not perfect, and there are also shortcomings to be improved for example the accuracy, size and costs of printed objects still need more improvement, yet global designers are still full of enthusiasm for attempts.

A good thing is that the R\&D of 3D printing technology is extremely valued in the country, which has been upgraded to a level of state strategy. in 2012, China 3d printing technology industrial alliance was set up; in 20103, China 3D printing technology industrial innovation center and incorporated in Nanjing, Zhuhai respectively; in 2013, 3d was integrated to the state 863 plan, and special funds were transferred to support the development of $3 \mathrm{~d}$ printing technologies, and 3D print industrial parks were built in cities across the country (Beijing, Shanghai, Zhuhai, Qingdao, etc.); In 2015, for the first time, the development of the $3 \mathrm{~d}$ print industry was upgrade to the development of a state strategic level; in 2016, the "13th FiveYear Plan" National Science and Technology Innovation Planning clearly shows the research plan for the development of $3 \mathrm{D}$ printing in the production of additive manufacturing so as to solve the material design and structural control.. R\&D metal, non-metallic and biological printing, breaking through key technologies in the structure and composite materials preparation and application to enhance the international competitiveness will lay a solid foundation for creating an excellent and convenient platform for soft outfit design.

\section{3D PRINTING TECHNOLOGY SUITABLE FOR SOFT OUTFIT DESIGN}

Fused Deposition Modeling (abbreviated as FDM) is a most frequently seen 3D printing technology in markets, which was solely registered cy American Stratasysys, and it works under the principle: materials are melted into liquid under high temperature and extruded out of a blow head for a solidified form, main materials include synthetic resin ABS plastic (Acrylonitrile butadiene Styrene copolymers), PC plastic (polycarbonate), ABS (polycarbonate composite), PLA (polylactic acid) and eutectic system metal and so on. The thickness of the hot extruded layer is $0.1 \mathrm{~mm}-0.5 \mathrm{~mm}$. With the technology used, the high-cost 3D printer may have a hot extruded layer of $0.1 \mathrm{~mm}$ as the thinnest, compared to the lowcost $3 \mathrm{~d}$ printer with a thickness of only $0.2-0.5 \mathrm{~mm}$, the accuracy of the objects printed is certainly different. Other 3D technologies include EBF (Electron beam freeform fabrication), DMLS (Direct Metal Laser-Sintering), EBM (electronic beam melting), SLM (Selective laser melting), SHS (Selective Heat Sintering), SLS (Selective Laser Sintering), 3DP (color 3D print), LOM (Laminated Object Manufacturing), SLA (Stereo lithography Appearance), DLP (Digital Light Processing), 2PP(nm 3D print) and so on.

For the soft outfits are involved in all kinds of types, styles and materials, the 3D print technologies mentioned above may be used for the indoor soft outfit design.

\section{APPLICATION OF 3D PRINTING TECHNOLOGY IN THE SOFT OUTFIT DESIGN}

\section{A. Application of 3D Printing Technology in Furniture Product Design}

In June 2016, a great number of 3D-based furniture works created by postgraduates were displayed at the graduation show of Tsinghua University Academy of Fine Arts, Beijing. Of which, a series of seats designed by a student are extremely interesting. According the proportion of 1:1, the design works was made by a $3 \mathrm{D}$ printer and placed in the exhibition hall, 
though its print accuracy needs to be further adjusted, yet it simplifies the process where abstract concept works are changed into physical forms from computer effect pictures, which disclose the "tip of the iceberg" for the feasibility and practical outlook of 3D printing in customized furniture, and as an experimental works, to assemble such a large 3d-based objects, the student is worth encouraging and applauding.

Let's go back to Aug 2014, Shanghai Zhangjiang New \& Hi-Tech Qingpu Park, it took only one day for Yingchuang Building Technology (Shanghai) Co., Ltd to build ten rough buildings, all of them were created by $3 \mathrm{D}$ printers, and the high efficiency ever shocked the world, which was widely reported. From then on within two years, this company showed 3D print works to the public around the world, including construction, wall, ground and customized furniture. For example: Beijing Phoenix Media Center, Beijing Strawberry Building and so on all adopted 3D print-based SCR (special glass fiber reinforced cement) materials. Furniture adopted FRP (special fiber composite materials) as the substrate and ware customized for Galaxy SOHO and other high-end places, with the Dubai palm tree charging piles included, the products have been sold to international markets.

\section{B. Application of 3D Prining Technology in Product Display Design}

Jonathan.Keep, a British artist, adopted a fluid of kaolin soil to extrude into a solid form, it works under the principle: mix ceramic powder or metal powder with a special adhesive according to a certain proportion to print diverse ceramic and metal-based 3D products (due to the special texture of ceramic, the primary models printed need to processed several times before marketing). FDC (Fused Deposition of Ceramics) is one of the MJS (Metro Jet System), adopting pure ceramic powder for printing, Jonathan.Keep has a product show on the website of his own. ${ }^{1}$ In 2012, a "3D Printing technology Exhibition" was held in London, where a variety of products made of ABS, PLA, PC, metal, ceramics and so on were shown such as sculptures, vases, tea sets, concept car models, mobile phones, jewelry, computer keyboards, and the rich patterns and high accuracy were out everyone's expectations. Among them, there were Digital Natives series vases created by designers Josh Henry and Materialise.

In the meantime, Chinese designers were also devoted to the research and production of kaoline-based 3D printers, through years of cooperation between experts from different fields, an initial result came into being. In 2015, led by Yang De'an, the Xiamen Smart Team successfully developed the first kaoline 3D printer $^{2}$, breaking through the traditional Chinese pottery wheel rotation pattern in manufacturing, and new kaoline materials were developed to match with the 3D extrusion disk forming process. Differing with the FDC, the kaoline-based 3D printer works on the basis of CDM, and the finished products printed need no sintering, whose costs were relatively low and easier to get started.

\footnotetext{
${ }^{1}$ [UK] Christopher Barnatt, 3d Printing : Second Edison, translated by Han Ying, Zhao Li, Posts \& Telecom Press, pp 39.

2 3D Print World, Vol. 22, pp 37.
}

The ceramic utensils produced by $3 \mathrm{D}$ printers are called digital kaoline by insiders and the furnishings indoor are called digital display.

In addition, Gao Junyi, a famous 3D Doodler designer at home personally produced a series of Warcraft exhibits ${ }^{3}$ on the basis of FDM-based miniature 3D printer - 3D Doodler. Spanish La Sagrada Família miniature model made by Cornelia Kuglmeier, a German artist, and Ozone gallery designed by Kengo Kuma, a Japanese architect were both galleries with public functions and a large display of public art. In addition to the FDM-based 3D Doodler, there are SLAbased light curing 3D Doodler. These mini 3D printers are easy to promote to the public, the operation is easier and the production cost is lower as well.

\section{Application of 3D Prining Technology in Light Product Design}

In Nov 2016, in the Shanghai 3D Print Industry Global Summit Tour (Shanghai station) Show, Bowen Studio printed a droplight named "Yang" 4 via 3D printers, according to the studio director, during the production, first of all, digital simulation is adopted to simulate the shape of a biology roaming in the water, and then nylon materials are used to print it out via 3D printers; another works named "Yang": parameters of impact are programmed to simulate external forces against rocks, and the parameters are used to impact the external surfaces of the model in the computer, and the formed effects are printed via 3D printers. The creativity is unique and novel, and the creature in virtual spaces are created in physical spaces via different materials, and designers may be so easy to touch the thing dreamed, how exciting it is!

\section{WAYS TO REALIZE 3D PRINT OF SOFT OUTFIT: ONLINE SERVICE PLATFORM}

\section{A. Break through Traditional Modes for Selection}

Thorough changes of traditional purchase pattern, owners or designers are unnecessary to seek for physical objects around the world and what they need to do is upload 3D model or self-made models to the 3D print platform to directly print it out, relevant materials and styles can be selected freely, there will be no the scene that owners or designers always complain most of soft outfit products produced in batches for marketing are almost the same, because each product is printed out solely at the request of users.

\section{B. Creation of Service Platforms}

How to promote the pattern and attract more to attend: the optimal method is to make use of the efficient and rapid 3D print platform to print the works at the request of users and then deliver to them quickly. Christopher Barnatt. a British scholar, made statistics ${ }^{5}$ about $3 \mathrm{D}$ print in his works, there were more than 10 online 3D print platforms in Europe and America, of which, Shapeways 3D print community was

\footnotetext{
3 3D Print World, Vol.22, pp 9

4 3D Print World, Vol.22, pp 21

5 [UK] Christopher Barnatt, 3d Printing : Second Edison, translated by Han Ying, Zhao Li, Posts \& Telecom Press, pp 67
} 
famous, which provided clients diverse 3D print service (tableware, jewelry and furniture, etc), as well as design software, through which, amateurs may also design works they need freely, the users can not only print 3D works of their own but also sell them at the online communities. From softwaremodel-print-distribution to sales, Shapeways improved the whole follow-up service chain so as to provide 3D print fans a perfect platform to share services. There are similar 3D online print platforms at home, for example, Shanghai Yinmengyuan Cloud Platform 3D print shares basically the same functions as Shapeways. The platforms integrate news, exchanges, model design, drawing print (Fig 3), online sales (Fig 4) and rapid transport, seen from these, the paces of domestic insiders are never stopped.

\section{CONCLUSION}

Everyone is trying the 3D print around the world, and diverse 3D printers are developed one after another, new techniques and new names make us a little busy. China has been devoted to the R\&D of additive manufacturing as well as the 3D print improvement techniques, who will be the final owner of the optimal 3D technique and hold the final initiative shall be determined in the future, best news will be coming soon.

\section{REFERENCES}

[1] [UK] Christopher Barnatt, 3d Printing : Second Edison, translated by Han Ying, Zhao Li [M] Beijing: Posts \& Telecom Press, 2014

[2] 3D Print World [J] Zhuhai: Recycling Times Media Corporation, 2016 (12) : 9-37.

[3] Zou Yunpeng, Primary Discussion on 3D Printing technology in Indoor Design Form Innovation [J] Modern Decoration, 2015(09):44.

[4] Wang Fangjun, Xia Yihan, Deng Deru, Application of 3D Printing technology in Indoor Design $[\mathrm{J}]$ Furniture \& Interior Design, 2014(08):14-15

[5] Li Jingjie, Zhang Rongqiang, Research on Application of 3D Printing technology in Customized Furniture [J], Furniture, 2015(05):17-21.

[6] Zou Yunpeng, Primary Discussion on 3D Printing technology in Indoor Design Form Innovation [J] Modern Decoration, 2015(09):44.

[7] Xinhua Finance, Formal Establishment of China 3D Print Technical \& Industrial Alliance. [DB/OL]. http://news.xinhuanet.com/fortune/201210/17/c_123833693.htm, Oct 17, 2012.

[8] White Bear, Shanghai Yingchuang, 3D Print-based houses have become a town. [DB/OL]. http://www.nanjixiong.com/thread-96799-1-1.html, Nov 13, 2016.

[9] Startsays official website in China. Comparison between FDM $\backslash$ Polyjet $\backslash S L S \quad$ Technologies. [DB/OL].http://web.stratasys.com/APJ-CN-PPC-ABC-Baidu-SearchNov15_New-PPC-

LP.html?utm_source=Baidu\&utm_medium $=$ cpc\&utm_campaign $=$ West _Tier2_3DP_Genral\&utm_content $=$ Technique\&utm_term $=20061$, Nov $\overline{13}, 2016$.

[10] Official Website of Yinmengyuan, [DB/OL]. http://www.yinmengyuan.com Jan 1, 2017.

[11] Official Website of Shapeways, [DB/OL]. https://www.shapeways.com Jan 1,2017 